\title{
RELAÇÃO DA RESPIRAÇÃO ORAL E HÁBITOS DE SUCÇÃO NÃO-NUTRITIVA COM ALTERAÇÕES DO SISTEMA ESTOMATOGNÁTICO
}

\section{Relation between oral breathing and nonnutritive sucking habits and stomatognathic system alterations}

\author{
Andrielle de Bitencourt Pacheco ${ }^{(1)}$, Ana Maria Toniolo da Silva (2), \\ Carolina Lisbôa Mezzomo ${ }^{(3)}$, Luana Cristina Berwig ${ }^{(4)}$, Aline Prade Neu ${ }^{(5)}$
}

\begin{abstract}
RESUMO
Objetivo: verificar a relação entre a respiração oral de diferentes etiologias e os hábitos de sucção não-nutritiva prolongados no estabelecimento de alterações estruturais do sistema estomatognático. Método: a amostra foi constituída por 78 crianças, entre 7 e 11 anos, sendo 36 meninos e 42 meninas divididas em grupos a partir dos hábitos de sucção não-nutritiva e modo respiratório. Todas as crianças foram submetidas à avaliação otorrinolaringológica, fonoaudiológica e odontológica. A análise dos dados foi realizada por meio do teste Qui-quadrado, considerando nível de significância de 5\%. Resultados: observou-se associação significante entre modo respiratório e postura de lábios; entre modo respiratório e palato duro; entre hábitos de sucção não-nutritiva e característica das bochechas. $\mathrm{Na}$ análise da associação entre modo respiratório e hábitos de sucção não-nutritiva com a postura habitual de lábios e com o palato duro também foi verificada significância estatística. Conclusão: verificou-se que a posição habitual alterada de lábios e de palato duro foi mais frequente nos grupos respiradores orais viciosos e obstrutivos. A posição assimétrica de bochechas foi mais frequente nas crianças com hábitos. A posição alterada de lábios e alterações do palato duro também foram mais frequentes nos respiradores orais independente da presença ou não de hábitos.
\end{abstract}

DESCRITORES: Sistema Estomatognático; Respiração Bucal; Sucção de Dedo; Comportamento de Sucção; Criança; Face

(1) Aluna do curso de Graduação em Fonoaudiologia da Universidade Federal de Santa Maria, UFSM, Santa Maria, RS.

(2) Fonoaudióloga; Professora Adjunta da Universidade Federal de Santa Maria - UFSM, Santa Maria, RS, Brasil; Doutora em Distúrbios da Comunicação humana pela Universidade Federal de São Paulo.

(3) Fonoaudióloga; Professora Adjunta da Universidade Federal de Santa Maria - UFSM, Santa Maria, RS, Brasil; Doutora em Letras pela Pontifícia Universidade Católica do Rio Grande do Sul.

(4) Fonoaudióloga; Mestranda do Programa de Pós-Graduação em Distúrbios da Comunicação Humana da Universidade Federal de Santa Maria - UFSM, Santa Maria, RS, Brasil.

(5) Fonoaudióloga; Mestranda do Programa de Pós-Graduação em Distúrbios da Comunicação Humana da Universidade Federal de Santa Maria - UFSM, Santa Maria, RS, Brasil.

Conflito de interesses: inexistente

\section{INTRODUÇÃO}

O sistema estomatognático é composto por estruturas pertencentes ao sistema digestório e respiratório, desempenhando as funções da deglutição, mastigação, fala e respiração. A forma adequada de processar a respiração é através da via nasal, que protege as vias aéreas inferiores e é preeminente ao crescimento e desenvolvimento craniofacial ${ }^{1-3}$.

A respiração nasal propicia o adequado crescimento maxilar e a postura adequada da mandíbula, que possibilita a correta intercuspidação entre arcadas dentárias e favorece a postura correta dos lábios, língua e bochechas ${ }^{4}$. Esta pode ser substituída por um padrão de suplência oral devido a causas obstrutivas ou viciosas 5 . 
A respiração oral obstrutiva ocorre quando existe algum impedimento mecânico à passagem do fluxo de ar por via nasal, podendo ocorrer por desvio de septo, hipertrofia de tonsilas faríngeas e/ou palatinas, entre outros ${ }^{6}$. Já a respiração oral viciosa decorre de hábitos orais prolongados, alterações musculares, edema transitório da mucosa nasal, obstrução reparada das vias aéreas e outros fatores ${ }^{1}$.

Tanto a respiração oral de etiologia obstrutiva quanto a de origem viciosa, são consideradas prejudiciais ao desenvolvimento harmônico da face, uma vez que podem gerar diversas adaptações do sistema estomatognático, tais como: eversão do lábio inferior, posição habitual dos lábios entreabertos e hipofunção do músculo orbicular da boca, língua com dorso elevado e ponta rebaixada no assoalho oral ou interposta anteriormente entre as arcadas dentárias, hiperfunção do músculo mentual, deglutição atípica, assimetrias faciais, respiração ruidosa, aumento da altura da face, palato duro profundo e/ou estreito e alterações de mordida e oclusão?.

Os hábitos orais deletérios, sobretudo os de sucção não-nutriva prolongados, dependendo da frequência, intensidade, duração e do tipo facial, também geram alterações no sistema estomatognático, tais como: hipodesenvolvimento da mandíbula, alteração na postura habitual dos lábios e da língua, alterações miofucionais orofaciais e deformidades nas estruturas ósseas e dentárias, sendo que estas alterações também favorecem a instalação da respiração oral|,8-12.

Partindo-se do pressuposto de que a associação entre respiração oral e hábitos de sucção não-nutritiva prolongados pode gerar maiores alterações miofuncionais orofaciais e de que diferentes etiologias da respiração oral podem determinar diferentes repercussões, realizou-se este estudo com o objetivo de verificar a relação entre a respiração oral de etiologia obstrutiva e funcional e os hábitos de sucção não-nutritiva prolongados no estabelecimento de alterações estruturais do sistema estomatognático.

\section{MÉTODO}

Esta pesquisa apresenta caráter quantitativo, transversal e contemporâneo. Foi realizada com crianças de quatro escolas públicas de ensino fundamental de Santa Maria - Rio Grande do Sul, que realizaram avaliação otorrinolaringológica, fonoaudiológica e odontológica.

A amostra foi constituída por 78 crianças de ambos os sexos. Os responsáveis pelas crianças assinaram o Termo de Consentimento Livre e
Esclarecido e as mesmas assentiram sua participação na pesquisa.

Os critérios de inclusão deste estudo foram: estar na faixa etária entre sete anos a 11 anos e 11 meses e serem caucasianas. As crianças que apresentavam histórico de tratamento fonoaudiológico e/ou ortodôntico, sinais evidentes de comprometimento neurológico e/ou síndromes e malformações craniofaciais foram excluídas.

A amostra foi submetida à avaliação do sistema estomatognático, que possibilitou a classificação do modo respiratório. O modo respiratório foi classificado como nasal quando havia uso predominante da cavidade nasal e algum ponto de selamento da cavidade oral; oronasal, quando era realizada pela boca e pelo nariz; oral, quando havia uso predominante da cavidade oral.

Posteriormente as crianças foram submetidas à avaliação otorrinolaringológica, para a realização do diagnóstico de respiração nasal ou respiração oral de acordo com a etiologia. A mesma foi composta por oroscopia, rinoscopia anterior e otoscopia, seguidos de nasofibrofaringoscopia.

Foram consideradas respiradoras nasais as crianças que, apresentaram na avaliação do sistema estomatognático modo respiratório nasal e na avaliação otorrinolaringológica, ausência de sinais e sintomas de respiração oral diurna e/ou noturna. Foram consideradas respiradoras orais as crianças que, na avaliação do sistema estomatognático, apresentaram modo respiratório oronasal ou oral e na avaliação otorrinolaringológica presença de sinais e sintomas de respiração oral diurna e/ou noturna.

O grupo de respiradores orais obstrutivos foi constituído pelas crianças que apresentaram na avaliação do sistema estomatognático modo respiratório oronasal ou oral e que no exame otorrinolaringológico apresentaram sinais e sintomas de respiração oral diurna e/ou noturna e diagnóstico de obstrução mecânica das vias aéreas superiores, ou seja, hipertrofia de tonsilas faríngeas e/ou palatinas graus 3 e $4^{13,14}$, associadas ou não à rinite.

O grupo de respiradores orais viciosos foi constituído pelas crianças que apresentaram na avaliação do sistema estomatognático modo respiratório oronasal ou oral e que no exame otorrinolaringológico apresentaram sinais e sintomas de respiração oral diurna e/ou noturna e diagnóstico de ausência de obstrução nas vias aéreas superiores. As crianças com edema transitório da mucosa nasal (rinite intermitente), tratadas ou não, e que mantinham a respiração oral habitual, mesmo quando sem obstrução, foram incluídas neste grupo.

Para classificação dos grupos de acordo com os hábitos de sucção não-nutritiva, uma 
fonoaudióloga entrevistou os pais, questionando quanto à presença e ao tempo de duração dos hábitos de chupeta e sucção digital e dados pertinentes ao desenvolvimento infantil, bem como, problemas de saúde atuais. Estes hábitos foram considerados prolongados, quando presentes por três anos ou mais, considerando-se a frequência, intensidade e duração ${ }^{4}$. Com base nestas informações, as crianças foram distribuídas nos seguintes grupos: grupo sem hábito $(\mathrm{SH})$ quando não apresentaram hábito de sucção não-nutritiva prolongados e grupo com hábito $(\mathrm{CH})$ quando apresentavam hábito de sucção de chupeta e/ou dedo por três anos ou mais.

Com base nas informações referentes à presença e ao tempo dos hábitos de sucção nãonutritiva obtidas com os pais e no diagnóstico otorrinolaringológico, as crianças também foram distribuídas nos seguintes grupos:

- RNSH: grupo respiração nasal sem hábitos de sucção não-nutritiva prolongados;

- RNCH: grupo respiração nasal com hábito de sucção de chupeta e/ou dedo por três anos ou mais;

- ROSH: grupo respiração oral sem hábitos de sucção não-nutritiva prolongados;

- ROCH: grupo respiração oral com hábito de sucção de chupeta e/ou dedo por três anos ou mais.

A avaliação do sistema estomatognático foi realizada por três fonoaudiólogas com experiência na área de motricidade orofacial. Considerou-se, nesta avaliação, os dados referentes à postura habitual de lábios e de língua, morfologia do palato duro e característica das bochechas.

Os dados foram classificados da seguinte forma:

- Posição habitual de lábios: (1) fechados quando os lábios apresentavam-se em posição adequada e leve contato; (2) entreabertos - quando os lábios estavam separados; (3) abertos - quando os lábios apresentavam-se separados e mandíbula visivelmente rebaixada.

- Posição de língua: (1) na papila palatina quando o terço anterior da língua alojava-se na região da papila palatina; (2) interdentalizada - observada quando a língua posicionava-se anteriormente, entre as arcadas dentárias; (3) no assoalho oral - quando a língua permanecia rebaixada.

- Palato duro: (1) normal - quando foi observada largura e profundidade adequados; (2) alterado - quando foi observado que o palato duro era profundo e/ou estreito.

- Característica das bochechas: (1) simétricas - quando existia semelhança entre tamanho, volume e altura das bochechas das hemifaces direita e esquerda; (2) assimétricas - quando foi observada discrepância entre tamanho, volume e altura das bochechas.

A avaliação odontológica foi realizada por um cirurgião-dentista que verificou os seguintes aspectos considerados neste estudo: as alterações oclusais ântero-posteriores (más oclusões Classe I, II e III de Angle), horizontais (sobressaliência, mordida cruzada anterior), verticais (sobremordida, mordida aberta anterior, mordida aberta posterior) e transversais (mordida cruzada posterior unilateral e/ou bilateral).

Os dados utilizados neste estudo fazem parte de um projeto previamente aprovado pelo Comitê de Ética em Pesquisa da Universidade Federal de Santa Maria - CEP/UFSM sob o protocolo de número 220.0.243.000-8.

Para verificar a relação entre os grupos formados e as alterações estruturais do sistema estomatognático, utilizou-se o teste Qui-Quadrado. Nas análises estatísticas foi utilizado nível de significância de 5\% $(p<0,05)$.

As análises foram realizadas utilizando-se o programa computacional SPSS versão 15.0 (2007).

\section{RESULTADOS}

Os dados referentes à relação entre modo respiratório e alterações nas estruturas do sistema estomatognático estão apresentados na Tabela 1.

A relação entre os hábitos de sucção não-nutritiva e alterações estruturais do sistema estomatognático estão expostos na Tabela 2.

$\mathrm{Na}$ Tabela 3, visualiza-se a relação entre modo respiratório e hábitos de sucção não-nutritiva associados às alterações estruturais do sistema estomatognático. 
Tabela 1 - Relação entre modo respiratório e alterações estruturais do sistema estomatognático

\begin{tabular}{|c|c|c|c|c|c|c|c|}
\hline \multirow{2}{*}{$\begin{array}{ll}\text { VARIÁVEIS } & \text { GRUPOS } \\
\end{array}$} & \multicolumn{2}{|c|}{ RN } & \multicolumn{2}{|c|}{ ROV } & \multicolumn{2}{|c|}{ ROO } & \multirow{2}{*}{$\mathbf{p}$} \\
\hline & $\mathbf{N}$ & $\%$ & $\mathbf{n}$ & $\%$ & $\mathbf{n}$ & $\%$ & \\
\hline \multicolumn{8}{|l|}{ Posição habitual de lábios } \\
\hline Fechados & 22 & 88 & 17 & 60,7 & 13 & 52,0 & \multirow{3}{*}{$0,017^{*}$} \\
\hline Entre abertos & 2 & 8,0 & 10 & 35,7 & 7 & 28,0 & \\
\hline Abertos & 1 & 4,0 & 1 & 3,6 & 5 & 20,0 & \\
\hline \multicolumn{8}{|l|}{ Posição habitual de língua } \\
\hline Papila palatina & 9 & 40,9 & 9 & 40,9 & 4 & 18,2 & \multirow{3}{*}{0,330} \\
\hline Entre os dentes & 5 & 31,3 & 7 & 43,8 & 4 & 25,0 & \\
\hline Assoalho da boca & 11 & 27,5 & 12 & 30,0 & 17 & 42,5 & \\
\hline \multicolumn{8}{|l|}{ Palato duro } \\
\hline Normal & 9 & 36,0 & 3 & 10,7 & 2 & 8,0 & \multirow{2}{*}{$0,017^{*}$} \\
\hline Alterado & 16 & 64,9 & 25 & 89,3 & 23 & 92,0 & \\
\hline \multicolumn{8}{|l|}{ Característica das bochechas } \\
\hline Simétricas & 14 & 56,0 & 14 & 50,0 & 14 & 56,0 & \multirow[t]{2}{*}{0,878} \\
\hline Assimétricas & 11 & 44,0 & 14 & 50,0 & 11 & 44,0 & \\
\hline \multicolumn{8}{|l|}{ Classificação da oclusão } \\
\hline Classe I & 17 & 68,0 & 13 & 46,4 & 14 & 56,0 & \multirow{3}{*}{0,338} \\
\hline Classe II & 7 & 28,0 & 9 & 32,1 & 7 & 28,0 & \\
\hline Classe I e II ou I e III & 1 & 4,0 & 6 & 21,4 & 4 & 16,0 & \\
\hline \multicolumn{8}{|l|}{$\begin{array}{l}\text { Alterações horizontais da } \\
\text { mordida }\end{array}$} \\
\hline Ausente & 10 & 40,0 & 8 & 28,6 & 11 & 44,0 & \multirow{3}{*}{0,424} \\
\hline Sobressaliência & 15 & 60,0 & 20 & 71,4 & 13 & 52,0 & \\
\hline Mordida cruzada anterior & 0 & 0 & 0 & 0 & 1 & 4,0 & \\
\hline \multicolumn{8}{|l|}{ Alterações verticais da mordida } \\
\hline Ausente & 11 & 44,0 & 10 & 35,7 & 15 & 60,0 & \multirow{4}{*}{0,537} \\
\hline Sobremordida & 9 & 36,0 & 10 & 35,7 & 8 & 32,0 & \\
\hline Mordida aberta anterior & 4 & 16,0 & 7 & 25,0 & 2 & 8,0 & \\
\hline Mordida aberta posterior & 1 & 4,0 & 1 & 3,6 & 0 & 0 & \\
\hline \multicolumn{8}{|l|}{$\begin{array}{l}\text { Alterações transversais da } \\
\text { mordida }\end{array}$} \\
\hline Ausente & 21 & 84,0 & 21 & 75,0 & 18 & 72,0 & \multirow{3}{*}{0,860} \\
\hline $\begin{array}{l}\text { Mordida cruzada posterior } \\
\text { unilateral }\end{array}$ & 3 & 12,0 & 6 & 21,4 & 6 & 24,0 & \\
\hline Mordida cruzada posterior bilateral & 1 & 4,0 & 1 & 3,6 & 1 & 4,0 & \\
\hline
\end{tabular}

*Significância pelo teste Qui-Quadrado $(p<0,05)$; RN=respiradores nasais; ROV=respiradores orais viciosos; ROO=respiradores orais obstrutivos.

\section{DISCUSSÃO}

Verificou-se, neste estudo, associação significante entre modo respiratório e posição habitual de lábios. No grupo de RN, apenas $12 \%$ apresentaram posição de lábios alterada. Nas crianças ROV a posição alterada de lábios ocorreu em aproximadamente $40 \%$ e no grupo ROO verificou-se que quase $50 \%$ das crianças apresentaram posição de lábios alterada (Tabela 1).

A literatura refere que a posição de lábios selados é aquela que ocorre com maior frequência nos respiradores nasais. $\mathrm{Na}$ ausência de obstruções nasais e/ou orofaríngeas, a permeabilidade nasal possibilita o adequado desenvolvimento da função da respiração por via nasal ${ }^{2}$. Por outro lado, na respiração oral as hipertrofias de tonsilas, edemas transitórios de mucosa nasal ou um simples hábito vicioso podem levar a criança a desenvolver e perpetuar alterações estruturais do sistema estomatognático, tais como a posição de lábios entreaberta ou aberta ${ }^{1,2}$.

Na posição habitual de lábios alterada, observase, geralmente, tensão de lábios diminuída, o que contribui para o selamento ineficiente dos lábios e ajustes motores inadequados ${ }^{15}$.

Em um estudo semelhante, realizado com 40 crianças nas idades entre seis e dez anos, foi 
Tabela 2 - Relação entre hábitos de sucção não-nutritiva e alterações estruturais do sistema estomatognático

\begin{tabular}{|c|c|c|c|c|c|}
\hline \multirow{2}{*}{$\begin{array}{ll}\text { VARIÁVEIS } & \text { GRUPOS } \\
\end{array}$} & \multicolumn{2}{|c|}{ SH } & \multicolumn{2}{|c|}{$\mathbf{C H}$} & \multirow{2}{*}{$\mathbf{p}$} \\
\hline & $\mathbf{n}$ & $\%$ & $\mathbf{n}$ & $\%$ & \\
\hline \multicolumn{6}{|l|}{ Posição habitual de lábios } \\
\hline Fechados & 28 & 71,8 & 24 & 61,5 & \multirow{3}{*}{0,124} \\
\hline Entre abertos & 6 & 15,4 & 13 & 33,3 & \\
\hline Abertos & 5 & 12,8 & 2 & 5,1 & \\
\hline \multicolumn{6}{|l|}{ Posição habitual de língua } \\
\hline Papila palatina & 14 & 35,9 & 8 & 20,4 & \multirow{3}{*}{0,143} \\
\hline Entre os dentes & 5 & 12,8 & 11 & 28,2 & \\
\hline Assoalho da boca & 20 & 51,3 & 20 & 51,3 & \\
\hline \multicolumn{6}{|l|}{ Palato duro } \\
\hline Normal & 9 & 23,1 & 5 & 12,8 & \multirow{2}{*}{0,238} \\
\hline Alterado & 30 & 76,9 & 34 & 87,2 & \\
\hline \multicolumn{6}{|l|}{ Característica das bochechas } \\
\hline Simétricas & 26 & 66,7 & 16 & 41,0 & \multirow{2}{*}{$0,023^{*}$} \\
\hline Assimétricas & 13 & 33,3 & 23 & 59,0 & \\
\hline \multicolumn{6}{|l|}{ Classificação da oclusão } \\
\hline Classe I & 26 & 66,7 & 18 & 46,2 & \multirow{3}{*}{0,186} \\
\hline Classe II & 9 & 23,1 & 14 & 35,9 & \\
\hline Classe I e II ou I e III & 4 & 10,3 & 7 & 17,9 & \\
\hline \multicolumn{6}{|l|}{ Alterações horizontais da mordida } \\
\hline Ausente & 16 & 41,0 & 13 & 33,3 & \multirow{3}{*}{0,440} \\
\hline Sobressaliência & 22 & 56,4 & 26 & 66,7 & \\
\hline Mordida cruzada anterior & 1 & 2,6 & 0 & 0 & \\
\hline \multicolumn{6}{|l|}{ Alterações verticais da mordida } \\
\hline Ausente & 21 & 53,8 & 15 & 38,5 & \multirow{4}{*}{0,056} \\
\hline Sobremordida & 15 & 38,5 & 12 & 30,8 & \\
\hline Mordida aberta anterior & 2 & 5,1 & 11 & 28,2 & \\
\hline Mordida aberta posterior & 1 & 2,6 & 1 & 2,6 & \\
\hline \multicolumn{6}{|l|}{ Alterações transversais da mordida } \\
\hline Ausente & 32 & 82,1 & 28 & 71,8 & \multirow{3}{*}{0,549} \\
\hline Mordida cruzada posterior unilateral & 6 & 15,4 & 9 & 23,1 & \\
\hline Mordida cruzada posterior bilateral & 1 & 2,6 & 2 & 5,1 & \\
\hline
\end{tabular}

*Significância pelo teste Qui-Quadrado $(\mathrm{p}<0,05)$; $\mathrm{CH}=$ grupo com hábitos de sucção não-nutritiva prolongados; $\mathrm{SH}=\mathrm{grupo}$ sem hábitos de sucção não-nutritiva prolongados.

verificada alta ocorrência de alterações na posição habitual dos lábios, presente em $67,05 \%$ da amostra ${ }^{16}$, indo ao encontro do presente estudo.

Quando os hábitos de sucção não-nutritiva foram analisados em conjunto com o modo respiratório, também foi evidenciada associação significante com a posição habitual de lábios. Frequências equivalentes entre a posição habitual de lábios alterados ocorreram nos grupos $\mathrm{ROSH}$ e $\mathrm{ROCH}$ (44\%) (Tabela 3). Desse modo, pode-se inferir que a presença de hábitos de sucção não-nutritiva prolongados não favoreceu alterações na posição habitual labial, ou seja, a respiração oral, independente da presença de hábitos de sucção nãonutritiva, pode ter favorecido a alteração na posição habitual de lábios. Pode-se inferir que a alteração do modo fisiológico da respiração impera nas alterações do sistema estomatognático, independente da associação com outros fatores contribuintes para alterações estruturais.

Com o resultado supracitado, constatou-se que o presente estudo não comprovou a hipótese existente de que os hábitos de sucção não-nutritiva prolongados contribuem para modificações na posição habitual dos lábios, como evidenciado em outros estudos 8,17 .

A literatura afirma que a posição de língua rebaixada no assoalho oral, muitas vezes favorece a alteração da morfologia do palato duro, uma vez que, esta deixa de exercer sua função modeladora e expansora ${ }^{7,8,18}$. Acredita-se que isso possa ter ocorrido neste estudo, pois foi verificada relação 
Tabela 3 - Relação entre modo respiratório, hábitos de sucção não-nutritiva prolongados e alterações estruturais do sistema estomatognático

\begin{tabular}{|c|c|c|c|c|c|c|c|c|c|}
\hline \multirow{2}{*}{$\begin{array}{l}\text { GRUPOS } \\
\text { VARIÁVEIS }\end{array}$} & \multicolumn{2}{|c|}{ RNSH } & \multicolumn{2}{|c|}{ RNCH } & \multicolumn{2}{|c|}{ ROSH } & \multicolumn{2}{|c|}{ ROCH } & \multirow{2}{*}{$\mathbf{p}$} \\
\hline & $\mathbf{N}$ & $\%$ & $\mathbf{n}$ & $\%$ & $\mathbf{n}$ & $\%$ & $\mathbf{n}$ & $\%$ & \\
\hline \multicolumn{10}{|l|}{ Posição habitual de lábios } \\
\hline Fechados & 8 & 72,7 & 14 & 100,0 & 16 & 59,3 & 14 & 56,0 & \multirow{3}{*}{$0,030^{*}$} \\
\hline Entre abertos & 2 & 18,2 & 0 & 0 & 10 & 37,0 & 6 & 24,0 & \\
\hline Abertos & 1 & 9,1 & 0 & 0 & 1 & 3,7 & 5 & 20,0 & \\
\hline \multicolumn{10}{|l|}{ Posição habitual de língua } \\
\hline Papila palatina & 1 & 9,1 & 8 & 57,1 & 7 & 25,9 & 6 & 24,0 & \multirow{3}{*}{0,090} \\
\hline Entre os dentes & 3 & 27,3 & 2 & 14,3 & 8 & 29,6 & 3 & 12,0 & \\
\hline Assoalho da boca & 7 & 63,6 & 4 & 28,6 & 12 & 44,4 & 16 & 64,0 & \\
\hline \multicolumn{10}{|l|}{ Palato duro } \\
\hline Normal & 3 & 27,3 & 6 & 42,9 & 2 & 7,4 & 3 & 12,0 & \multirow{2}{*}{$0,028^{*}$} \\
\hline Alterado & 8 & 72,7 & 8 & 57,1 & 25 & 92,6 & 22 & 88,0 & \\
\hline \multicolumn{10}{|c|}{ Característica das bochechas } \\
\hline Simétricas & 3 & 27,3 & 11 & 78,6 & 13 & 48,1 & 15 & 60,0 & \multirow{2}{*}{0,063} \\
\hline Assimétricas & 8 & 72,7 & 3 & 21,4 & 14 & 51,9 & 10 & 40,0 & \\
\hline \multicolumn{10}{|l|}{ Classificação da oclusão } \\
\hline Classe I & 7 & 63,6 & 10 & 71,4 & 11 & 40,7 & 16 & 64,0 & \multirow{3}{*}{0,336} \\
\hline Classe II & 3 & 27,3 & 4 & 28,6 & 10 & 37,0 & 5 & 20,0 & \\
\hline Classe I e II ou I e III & 1 & 9,1 & 0 & 0 & 6 & 22,2 & 4 & 16,0 & \\
\hline \multicolumn{10}{|l|}{$\begin{array}{l}\text { Alterações horizontais da } \\
\text { mordida }\end{array}$} \\
\hline Ausente & 7 & 63,6 & 3 & 21,4 & 6 & 22,2 & 13 & 52,0 & \multirow{3}{*}{0,055} \\
\hline Sobressaliência & 4 & 36,4 & 11 & 78,6 & 21 & 77,8 & 11 & 44,0 & \\
\hline Mordida cruzada anterior & 0 & 0 & 0 & 0 & 0 & 0 & 1 & 4,0 & \\
\hline \multicolumn{10}{|l|}{$\begin{array}{l}\text { Alterações verticais da } \\
\text { mordida }\end{array}$} \\
\hline Ausente & 4 & 36,4 & 7 & 50,0 & 11 & 40,7 & 14 & 56,0 & \multirow{4}{*}{0,263} \\
\hline Sobremordida & 3 & 27,3 & 6 & 42,9 & 8 & 29,6 & 9 & 36,0 & \\
\hline Mordida aberta anterior & 3 & 27,3 & 1 & 7,1 & 8 & 29,6 & 1 & 4,0 & \\
\hline Mordida aberta posterior & 1 & 9.1 & 0 & 0 & 0 & 0 & 1 & 4,0 & \\
\hline \multicolumn{10}{|l|}{$\begin{array}{l}\text { Alterações transversais da } \\
\text { mordida }\end{array}$} \\
\hline Ausente & 7 & 63,6 & 14 & 100,0 & 20 & 74,1 & 18 & 72,0 & \multirow{3}{*}{0,414} \\
\hline $\begin{array}{l}\text { Mordida cruzada posterior } \\
\text { unilateral }\end{array}$ & 3 & 27,3 & 0 & 0 & 6 & 22,2 & 6 & 22,0 & \\
\hline $\begin{array}{l}\text { Mordida cruzada posterior } \\
\text { bilateral }\end{array}$ & 1 & 9,1 & 0 & 0 & 1 & 3,7 & 1 & 4,0 & \\
\hline
\end{tabular}

*Significância pelo teste Qui-Quadrado $(\mathrm{p}<0,05)$; RNSH=respiradores nasais sem hábitos de sucção não-nutritiva prolongados; $\mathrm{RNCH}=$ respiradores nasais com hábitos de sucção não-nutritiva prolongados; $\mathrm{ROSH}=$ respiradores orais sem hábitos de sucção nãonutritiva prolongados; $\mathrm{ROCH}=$ respiradores orais com hábitos de sucção não-nutritiva prolongados.

significante entre alteração do palato duro e modo respiratório. No grupo ROV, verificou-se que $80 \%$ das crianças apresentaram morfologia do palato alterado e nas ROO essa proporção aumentou para $92 \%$ (Tabela 1). A partir desses resultados, acredita-se que a respiração oral possa afetar a morfologia do palato duro.

Quando ocorre o impedimento à passagem do ar pelo nariz não há uma efetivação da reabsorção óssea na parte interna das fossas nasais e a deposição óssea na parte externa. Isso acaba por não promover o distanciamento dos arcos da órbita, faces nasal e oral do palato, arco maxilar, seios paranasais e arcos zigomáticos, podendo haver alteração morfológica no palato duro ${ }^{19,20}$.

$\mathrm{Na}$ análise conjunta do modo respiratório e hábitos de sucção não-nutritiva com o palato duro (Tabela 3), também foi verificada significância estatística. Nesse caso, a alteração do palato prevaleceu nas crianças $\mathrm{ROSH}$ e $\mathrm{ROCH}$, sendo as porcentagens semelhantes em ambos os grupos. Desse modo, acredita-se que a presença dos hábitos 
de sucção não foi determinante para a alteração morfológica do palato duro. No entanto, salientase cautela na interpretação destes achados porque as alterações foram frequentes nos grupos RNSH e $\mathrm{RNCH}$, sendo preciso considerar que o palato é uma estrutura de difícil avaliação clínica e que não existem parâmetros entre os profissionais que o avaliam $^{21}$.

A alteração morfológica do palato duro pode estar relacionada ao crescimento e desenvolvimento do complexo craniofacial, perfil facial, fatores genéticos e alterações estruturais na face ${ }^{22}$. Tais causas podem elucidar a causa da grande frequência da alteração morfológica do palato duro no grupo de crianças RN (Tabela 1), RNSH e RNCH (Tabela 3).

Ao se verificar a relação entre hábitos de sucção não-nutritiva e característica das bochechas encontrou-se associação significante (Tabela 2), observando que $59 \%$ das crianças $\mathrm{CH}$ apresentaram bochechas assimétricas.

Os hábitos de sucção não-nutritiva prolongados causam desequilíbrio das forças que naturalmente atuam na cavidade oral, podendo favorecer a flacidez da musculatura das bochechas ${ }^{8}$, dificultando o padrão mastigatório bilateral alternado. Desta forma, uma das bochechas pode deixar de reconduzir os alimentos dos vestíbulos para as faces oclusais durante a mastigação, gerando assimetria entre essas estruturas ${ }^{16}$.

No presente trabalho, não foi verificada associação estatisticamente significante entre os grupos formados a partir do modo respiratório, hábitos de sucção e alterações oclusais nos planos ânteroposterior, horizontal, vertical e transversal com os grupos de estudo (Tabelas 1, 2 e 3).

Espera-se que, na presença da respiração oral, existam alterações ortodônticas. Entre as alterações da chave de molar, verifica-se a prevalência da má oclusão Classe $\mathrm{I}^{23}$, seguida de má oclusão Classe II. A relação entre hábitos orais e má oclusão afeta de maneira significante a estrutura dentária ${ }^{24}$. A literatura afirma que a respiração oral pode influir na chave de molar, proporcionar mordida cruzada posterior e sobressaliência ${ }^{20,25-29}$. Os hábitos de sucção não-nutritiva associam-se frequentemente com mordida aberta anterior e sobressaliência 8,30 .

As consequências da respiração oral e dos hábitos de sucção podem ser desfavoráveis ao sistema estomatognático, portanto, destaca-se a importância ao trabalho multidisciplinar ${ }^{27}$ envolvendo fonoaudiólogos, otorrinolaringologistas e dentistas, bem como, outros profissionais para melhores resultados terapêuticos.

\section{CONCLUSÃO}

De acordo com a pesquisa realizada, conclui-se que:

- A posição alterada de lábios e de palato duro foi mais frequente nos grupos respiradores orais viciosos e obstrutivos, com diferença estatística;

- A assimetria das bochechas foi mais frequente nas crianças com hábitos, apresentando diferença estatisticamente significativa em relação às crianças sem hábitos de sucção não-nutritiva prolongados;

- A posição habitual alterada de lábios e alterações do palato duro também foram mais frequentes nos respiradores orais, independente da presença de hábitos, com significância estatística na comparação entre os grupos de respiradores nasais com e sem hábitos de sucção não-nutritiva prolongados e os grupos de respiradores orais com e sem hábitos de sucção.

\section{AGRADECIMENTOS}

Agradecemos ao médico Rodrigo Agne Ritzel pelas avaliações otorrinolaringológicas, ao dentista Marlon Munhoz Montenegro pelas avaliações odontológicas e as fonoaudiólogas Geovana de Paula Bolzan e Luane de Moraes Boton pelas avaliações antroposcópicas do sistema estomatognático. 


\section{ABSTRACT}

Purpose: to investigate the relationship between oral breathing of different etiologies and persisting non-nutritive sucking habits in establishing structural alterations in the stomatognathic system. Method: the sample comprised 78 children between 7 and 11 year old, 36 boys and 42 girls, divided in two groups based on non-nutritive sucking habits and breathing mode. All children underwent otolaryngological, speech-language and dentistry evaluations. Data analysis was performed using Chisquare test considering significance level of $5 \%$. Results: there was significant association between breathing mode and lips posture; between breathing mode and hard palate; between nonnutritive sucking habits and cheek posture. In the analysis of the association between breathing mode and nonnutritive sucking habits with the habitual lips posture and hard palate, we also forund a statistical significance. Conclusion: it was found that the altered lips posture and hard palate was more frequent in the vicious and obstructive mouth breathers groups. The asymmetrical cheeks posture was more frequent among children with habits. The altered lips posture and hard palate alterations were also more frequent in oral breathers regardless of the presence or absence of any habits.

KEYWORKS: Stomatognathic System; Mouth Breathing; Fingersucking; Sucking Behavior; Child; Face

\section{REFERÊNCIAS}

1. Marchesan IQ. Avaliação e Terapia dos Problemas da Respiração. In: Fundamentos em Fonoaudiologia - Aspectos Clínicos da Motricidade Oral. $2^{2}$ ed. Rio de Janeiro: Guanabara-Koogan; 2005. p. 23-36.

2. Rodrigues HOSN, Faria SR, Paula FSG, Motta AR. Ocorrência de respiração oral e alterações miofuncionais orofaciais em sujeitos em tratamento ortodôntico. Rev CEFAC. 2005;7(3):356-62.

3. Lemos CM, Junqueira PAS, Gomez MVSG, Faria MEJ, Basso SC. Estudo da relação entre a oclusão dentária e a deglutição no respirador oral. Arq Int Otorrinolaringol. 2006;10(2):114-8.

4. Rodrigues JA, Bolini PDA, Minarelli-Gaspar AM. Hábitos de sucção e suas interferências no crescimento e desenvolvimento craniofacial da criança. Odontologia. Clín.-Científ. 2006;5(4):257-60.

5. Vianna-Lara MS, Caria PHF. Electromyographic analysis of the upper lip in nose and mouth breathers. Braz J Oral Sci. 2006;5(19):1203-8.

6. Imbaud T, Wandalsen G, Nascimento Filho E, Wandalsen NF, Mallozi MC, Solé D. Respiração bucal em pacientes com rinite alérgica: fatores associados e complicações. Rev Bras Alerg Imunopatol. 2006;29(4):183-7.

7. Cattoni DM, Fernandes FD, Di Francesco $\mathrm{RC}$, Latorre MRDO. Características do sistema estomatognático de crianças respiradoras orais: enfoque antroposcópico. Pró-Fono Rev Atual Cient. 2007;19(4):347-51.
8. Degan VV, Puppin-Rontani RM. Remoção de hábitos e terapia miofuncional: restabelecimento da deglutição e repouso lingual. Pró-Fono Rev Atual Cient. 2005;17(3):375-82.

9. Branco A, Ferrari GF, Weber SAT. Alterações orofaciais em doenças alérgicas de vias aéreas. Rev Paul Pediatr. 2007;25(3):266-70.

10. Lemos CM, Wilhelmsen NSW, Mion O, Mello Júnior JF. Alterações funcionais do sistema estomatognático em pacientes com rinite alérgica. Int Arch Otorhinolaryngol. 2007;11(4):380-6.

11.Rodrigues JA, Bolini PDA, Minarelli-Gaspar AM. Hábitos de sucção e suas interferências no crescimento e desenvolvimento craniofacial da criança. Odontologia. Clín.-Científ. 2006;5(4):257-60.

12. Almeida FL, Silva AMT, Serpa EO. Relação entre má oclusão e hábitos orais em respiradores orais. Rev. CEFAC. 2009; 1(11): 86-93.

13. Brodsky L, Koch RJ. Anatomic correlates of normal and diseased adenoids in children. Laryngoscope. 1992;102(11):1268-74.

14. Parich SH, Coronel M, Lee J, Brown S. Validation of a new grading system for endoscopic examination of adenoid hypertrophy. Otolaryngol Head Neck Surg. 2006;135(5):684-7.

15. Borghi LC, Roldão FTF, Mariatto M. Postura habitual de lábios mais encontradas em crianças. Rev CEFAC. 2003;5(3):227-30.

16. Andrade FV, Andrade DV, Araújo AS, Ribeiro ACC, Deccax LDG, Nemr K. Alterações estruturais de órgãos fonoarticulatórios e más oclusões dentárias em respiradores orais de 6 a 10 anos. Rev CEFAC. 2005;7(3):318-25. 
17. Verrastro AP, Ashima AY, Ideriha P, Stefani FM, Rodrigues CRMD, Wanderley MT. Características oclusais e miofuncionais orais das crianças atendidas na Clínica de Odontopediatria da Faculdade de Odontologia da USP. Rev Inst Ciênc Saúde. 2009;27(4):394-9.

18. Oliveira MO, Vieira MM. Influência da respiração bucal sobre a profundidade do palato. Pró-Fono Rev Atual Cient. 1999;11(1):13-20.

19. Di Francesco RC. Consequências da respiração oral. In: Krakauer LH, Di Francesco RC, Marquesan IQ. Conhecimentos essenciais para entender bem a respiração oral. São José dos Campos: Pulso; 2003. p. $19-25$.

20. Cappellette M, Carlini D, Pignatari SS, Cruz OL, Weckx LL. Rinometria acústica em crianças submetidas à disjunção maxilar. $\mathrm{R}$ Dental Press Ortodon Ortop Facial. 2006;11(2):84-92.

21. Marchesan IQ. Motricidade oral. São Paulo: Pancast; 1993.

22. Enlow DH, Hans MG. Noções Básicas sobre Crescimento Facial. São Paulo: Santos, 1998.

23. Berwig LC, Silva AMT, Busanello AR, Almeida FL, Bolzan GP, Tais Regina Hennig TR. Alterações no modo respiratório, na oclusão e na fala em escolares: ocorrências e relações. Rev CEFAC. 2010;12(5):795-802.

24. Souza DFRK, Valle MAS, Pacheco MCT. Relação clínica entre hábitos de sucção, má oclusão, aleitamento e grau de informação prévia das mães. R Dental Press Ortodon Ortop Facial. 2006; 1(6):81-90.

25. Menezes VA de, Leal RB, Pessoa RS, Pontes RMES. Prevalência e fatores associados à respiração oral em escolares participantes do projeto Santo Amaro-Recife, 2005. Rev Bras Otorrrinolarigol. 2006;72(3):391-9.

26. Sies ML, Farias SR, Vieira MRM. Respiração oral: relação entre o tipo facial e a oclusão dentária em adolescentes. Rev Soc Bras Fonoaudiol. 2007;12(3):191-8.

27. Izuka ZN. A influência da respiração oral na oclusão dentária: uma visão geral da literatura. ACTA ORL/Técnicas em Otorrinolaringologista. 2008;26(3):151-4.

28. Oliveira CF, Busanello AR, Silva AMT. Ocorrência de má oclusão e distúrbio articulatório em crianças respiradoras orais de escolas públicas de Santa Maria, Rio Grande do Sul. RGO. 2008;56(2):169-74. 29. Nunes WR, Di Francesco RC. Variation of Patterns of Malocclusion by Site of Pharyngeal Obstruction in Children. Arch Otolaryngol Head Neck Surg. 2010;136 (11):1116-20.

30. Lima GN, Cordeiro CM, Justo JSJ, Rodrigues LCB. Mordida aberta anterior e hábitos orais em crianças. Rev Soc Bras Fonoaudiol. 2010;15(3):369-75.
http://dx.doi.org/10.1590/S1516-18462011005000124

RECEBIDO EM: 22/12/2010

ACEITO EM: 05/05/2011

Endereço para correspondência:

Andrielle de Bitencourt Pacheco

Visconde de Pelotas, 505 ap. 208

Santa Maria - RS

CEP: 97010-440

E-mail: andrielle.pacheco@gmail.com 